\title{
Maslow Theory Revisited-Covid-19 - Lockdown Impact on Consumer Behaviour
}

\author{
Dr. Priya Dwivedia ${ }^{a}$ and Dr. Jyoti Badge ${ }^{b}$ \\ Assistant Professor- Lucknow University (Guest Faculty) \\ ${ }^{\text {b} A s s i s t a n t ~ P r o f e s s o r-~ V I T, ~ B h o p a l ~}$
}

Article History: Received: 11 January 2021; Accepted: 27 February 2021; Published online: 5 April 2021

\begin{abstract}
The current study is attempting to derive the reference to the hierarchy of Maslow, where the consumers were placed before the arrival of Covid-19 and during the lockdown time. Consumer behavior consists of cognitive, emotional or physical activities in which people pick, purchase, consume and dispose of products and services to satisfy their choices and expectations. Abraham Maslow defined hierarchy of needs in different forms viz Physiological, Safety,Social,Esteem and Selfactualization needs. A multiplicity of competing factors influences human behaviour and thereby needs and requirements.Recognition of needs is essential as the initial step for market participants in the supply chain. At the same time recognising where the needs of consumers will alter is parallelly significant for smooth functioning of market processes and securing profitability along with capturing the trend. In the present study with the help of primary survey need recognition or any sort of variation therein, pre and during the Covid-19 lockdown periodare traced within the conceptual framework of Maslow Hierarchy of needs theory.
\end{abstract}

Keywords: Consumer behaviour, Maslow Hierarchy of needs, Covid-19, Lockdown time,Trends of trade

\section{Introduction}

A pneumonia of unidentified origin experienced all over the world the outbreak has been declared a public health emergency of worldwide significance on 11 February 2020, WHO termed a new Coronavirus disease: COVID-19(21). In addition to the highnumber of cases of local Coronavirus disease in 2019 (COVID-19), lockdowns have been introduced by many countries to curtail travel and population contacts and thus prevent transmission(24). The government has used social distancing or lockdown policy in the absence of preventive vaccination, enforcing travel restrictions, shutting busy public areas and academic institutions.In the situation of lockdown consumer is not allowed to roam freely, there may some direct or indirect restrictions on consumer buying process which may affect or change the original and natural behaviour of consumer(23).

Although Consumer behaviour evolves over time to comply with their desires, beliefs yet many underlying environmental factors affect them most. Consumer behaviour alter to fit the requirements of immediate environment and surroundings. Consumer behavior articulates utilization, decide to buy and attitude that influence consumers in their intent to buy.Companies that relent in the current customer orientation could dispel the competitive advantages. The effort to understand consumer behavior has thus gained all time importance. Such actions are crucial in shining light on decision-makers in formulating policies across several perspectives.

\section{Conceptual framework}

Consumer behaviour can consist in: the intellectual, emotional and physical behaviours in which people select, consume, use and dispose of goods and services to fulfil choices and aspirations(14). Need recognition is required as the initial step in procurement process with respect to traders. A consumer may be forced to purchase a product for comfort, style, prestige, self-pride or anything else(11).

Maslow's Theory

In his 1943 paper, “A Theory of Human Motivation,” American psychologist Abraham Maslow proposed the idea of a psychological hierarchy of needs in human beings(2).

1) Physiologicalneeds

These are the basic needs, like food, water, sleep, warmth

2) Safetyneeds

Persons in a given situation ought to feel safe.

3) Socialneeds

Human beings desire love, and others tend to acknowledge it. They like to join parties, organizations and other connections.

4) Esteemneeds

People want to be treated with admiration and respect.

5) Self-actualizationneeds

People want their full potential, including all creative activities, to be fulfilled. 


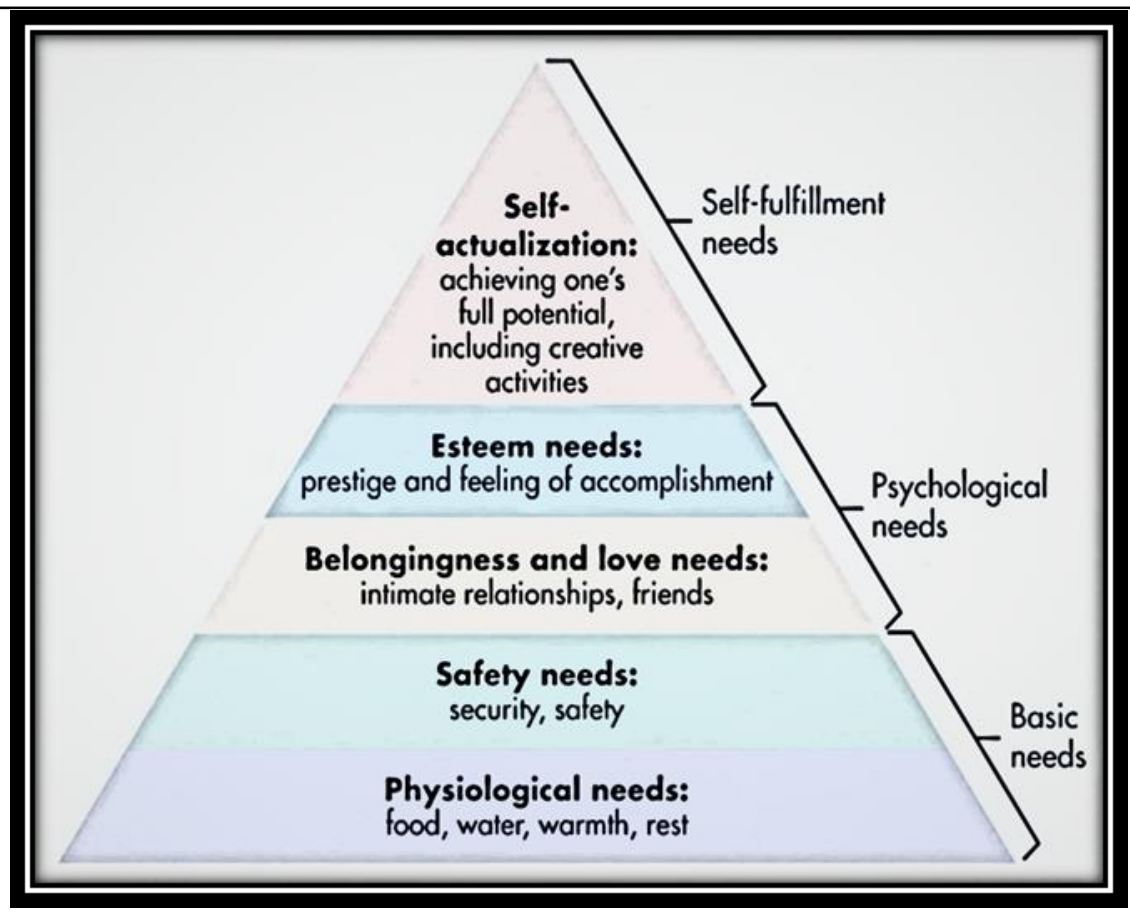

Figure 1: Maslow Hierarchy of Human Needs

[Reference-Consumer Behaviour - Sixth Edition Leon G. Schiffman \& Leslie Lazar Kanuk Prentice Hall of India Pvt. Ltd. (13)]

People who have all the other needs beneath the pyramid will need more and more. These needs demonstrate how they look at themself and how they are perceived.In the present work key information about the consumers' needs is tried to extract in reference to Maslow's hierarchy where they were situated before the advent of Covid19 and during the lockdown period.Abraham Maslow, a pioneer in human behavioural psychology, established Maslow's hierarchy of needs. The hierarchy was originally created to further understand the connection between basic human needs and human desires. Hierarchy, often find in the shape of pyramid, is classified into five groups. Clearly acknowledged, once we have the essential human requirements at the edge of the ladder, we cannot aspire to satisfy any more wishes. We step up in a competitive economic system, therefore the survival and growth of firms requires accurate knowledge about consumers, how they buy, why they buy, and where they buy and what they buy. All social scientists are agreed upon that human behaviour is influenced by a multiplicity of interacting forces and that it presents a very considerable challenge to anyone who attempts to unravel the motivating factors that shape it (8).

Foxall, G. R. (Ed.) (2002) Consumer Behaviour Analysis: Critical Perspectives. London and

New York: Routledge.

Foxall, G. R. (Ed.) (2002) Consumer Behaviour Analysis: Critical Perspectives. London and

New York: Routledge.

\section{Literature Review}

Belk (1975) in his paper suggested that clear knowledge of situation variables can greatly improve the ability to describe and comprehend cognitive acts of consumers. It offered a description and explanation of situations; he summarises current studies and it considers impacts on consumer research(17).

Dijksterhuis\& Smith et.al (2008) in their article suggest that implicit environmental signals also greatly affect consumer behaviour. Using grocery shopping as an example. They assert first that the conventional consumer selection paradigm focused on conscious information processing leaves plenty of variation to understand. They suggest instead that certain decisions are taken inadvertently and deeply influenced by the climate. Their claim is focused on research into the relationship between perception - behaviour and automatic achievement of objectives (4).

Ardura\&-López F.Jet al. (2017) provide the comprehensive overview of the recent research contributions made to a wide variety of problems that exacerbate the field of online customer behaviour. From the early nineties till now, the researchers offer a diverse view of research subjects, examined from the marketing viewpoint.This methodology can be useful not only for further structuring or improving the knowledge academics have acquired in the area, but also as a reference and repository of guidelines for future study (15).

With their paper Benson \&Dundis JD (2003), extend the Hierarchy of Needs Paradigm of Maslow to the complexities of identifying and empowering workers in a constantly evolving field of health care.The researchers provide a new viewpoint on how the Maslow Paradigm can be specifically applied to existing employee issues when used in business / organizational settings: the desire for stability and independence from tension, social identity, self-esteem, self-actualization, altered work / social conditions, and unique learning and self-definition opportunities(19). 
Kira Lussier (2019) explores the effect on the American administration of the hierarchy of needs of the psychologist Abraham Maslow,via case studies of job overhaul programmes at Texas Instruments and marketing company Young \& Rubicam 's management instruction, and traces how a roster of management experts transformed the hierarchy of needs into management.(12)

The authorsAlajmi\&Alasousi(2019) analyzed the levels of motivation and needs of university library workers with the aid of this article, following Maslow's hierarchy of needs to analyze the motivation of individuals. While respondents largely accepted that their needs at each of the five levels of the hierarchy of Maslow were fulfilled, they indicated higher levels of satisfaction with their self-actualization and social needs. Self-actualization is the summit of the inspiration philosophy of Maslow, reflecting the search to achieve one's maximum potential as an entity(6).

Maslow 's common account of the work contradicts key aspects of the original work, namely, the preconditions for fulfilment need and the role of knowledge. When the researchers studied storeys shared by refugees, much observations were generated by these well-known facets of his philosophy. Liberty is achieved at varying stages in the developing countries.

Roelien Goede \&Van Burken (2019) argue that freedom is an "end" and bureaucratic, conflicting with Maslow's view. A refugee cannot experience freedom without knowledge(16).

This research by Ryan\& Coppola et al. (2020)lays out a structure to define a direction forward. It focuses on the specifications, legislation and guidance, influences and application of the benchmark. To ensure societal stability and survival, those who want a strong recovery from the COVID-19 pandemic need to follow an evidence-based system now.

The vulnerability must be recognized by decision-makers and how the Maslow hierarchy of needs and the social determinants of health will influence entire public policies. When addressing the crisis, aligning decisions with social desires would help ensure that all sectors of society are catered for and fulfilled.

In order to promote the resumption of societal pillars such as trade, schooling, and jobs in a way that safeguards those most vulnerable to COVID-19, this must notify the mechanism of gradual easing of lockdowns(5).

\section{Research Methodology}

a. Research Goal

This study tries to trace whether pandemic Covid-19 - health crisis situation affects consumer behaviour in any way. Maslow's theory is very basic of consumer need analysis and this current study analyzes its applicability in the covid-19 pre and during status of mind of Consumers with respect to their needs.

b. Research Question

Maslow in his analysis described about five different needs and presented them in a hierarchical mechanism. The research question of the current study is- Whether the consumer belonged to the same hierarchy during the lockdown period as they were before lockdown?

c. Research Design

This study investigates impacts of covid-19 lockdown on consumer behaviour with the help of Maslow's theory. The problem of study is to identify any sort of behavioural changes that pre and during the lockdown period, as a result there were changes of hierarchy. It is asked to them-Are they aware about their real needs?And at which position they were pre and during lockdown. A cross-sectional online survey is conducted.The questionnaire would distribute to random population and the survey resultwould be analyzed using SPSS 25 software. The sampling is based on non- probabilistic convenience and the sample size is 518 .

d. Hypothesis

Null Hypothesis $(\mathrm{H} 0=0)$ :There is no change in the needs and hierarchy of Consumers as suggested by the Maslow theory.

Alternative Hypothesis $(\mathrm{H} 1 \neq 0)$ :There is change in the needs and hierarchy of Consumers as suggested by the Maslow theory.

Testing of Hypothesis - For testing of hypothesis paired t-test is applies in order to know any significant difference between the two status of consumer's hierarchy.

\section{Results}

For coded categorical variables, the value label(s) that should be associated with each category abbreviation. Value labels are useful primarily for categorical (i.e., nominal or ordinal) variables, especially if they have been recorded as codes (e.g., 1, 2, 3). Table-1 shows the codes of categorial variables.

Table 1: Coding of Qualitative Variable

\begin{tabular}{|l|l|}
\hline Psychological needs- Food, Water, Shelter & 1 \\
\hline Safety needs- $\quad$ Security, Protection & 2 \\
\hline Social Needs- $\quad$ Sense of Belonging, family, friends, love & 3 \\
\hline Esteem Needs- Self -esteem, recognition, status & 4 \\
\hline Self-actualization- self -development and realization & 5 \\
\hline
\end{tabular}

Descriptive Statistics of Pre and During Covid-19 lockdown period

Table 2: Descriptive Statistics 


\begin{tabular}{|c|l|c|c|}
\hline \multicolumn{2}{|c|}{} & Pre & During \\
\hline \multirow{2}{*}{$\mathrm{N}$} & Valid & 518 & 518 \\
\cline { 2 - 4 } & Missing & 0 & 0 \\
\hline \multicolumn{2}{|c|}{ Mean } & 2.95 & 2.53 \\
\hline Median & 3.00 & 2.00 \\
\hline Mode & 3 & 2 \\
\hline Minimum & 1 & 1 \\
\hline \multicolumn{2}{|c|}{ Maximum } & 5 & 5 \\
\hline
\end{tabular}

Table 2: shows side-by-side comparison of the descriptive statistics for the two variables. This allows us to quickly make the following observations about the data:

- $\quad \mathrm{N}=518$ and no missing value.

- $\quad$ The maximum value 5 (Self-actualization) and 1 (Psychological needs) minimum value.

Table 3: Frequency table of Pre and During Covid-19 Period

\begin{tabular}{|l|l|c|c|}
\hline \multicolumn{2}{|l|}{} & Pre & During \\
\hline \multirow{2}{*}{ Psychological needs } & 92 & 128 \\
\cline { 2 - 4 } Safety needs & 82 & 180 \\
\hline Social Needs & 190 & 102 \\
\hline Esteem Needs & 70 & 26 \\
\cline { 2 - 4 } & Self-actualization & 84 & 82 \\
\hline Total & 518 & 518 \\
\hline
\end{tabular}

Table 3: shows the frequency distribution of pre and during Covid-19 period. It was observed that in the pre Covid-19 era people focus more on social needs as compared to other needs. Whereas during covid-19 people are more aware about safety needs.

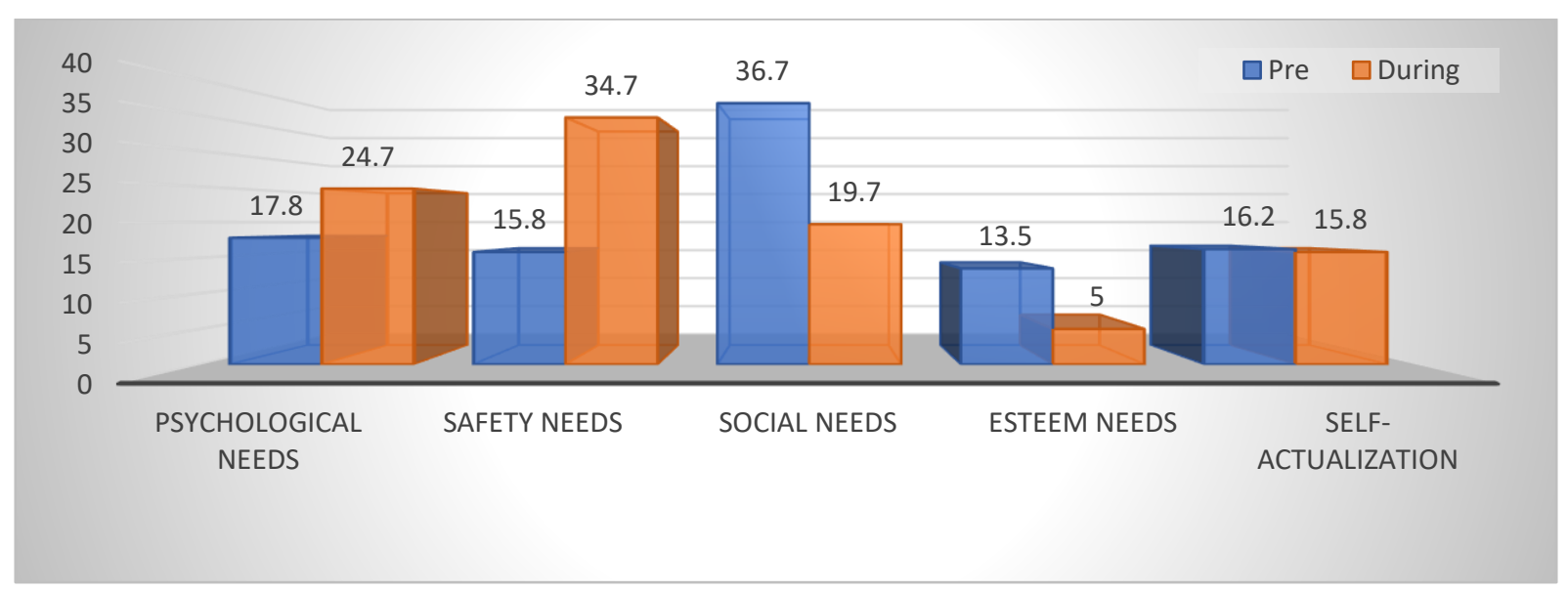

Figure 2: Bar Graph of Behavioural Needs and Frequency Percentage

Figure 2 gives the information through bar graph of different behavioural needs of people of pre and during covid-19 period.

t-test Analysis

The dependent t-test (called the paired-samples t-test in SPSS Statistics) compares the means between two related groups on the same continuous, dependent variable.

SPSS Statistics generates three tables in the Output Viewer under the title "t-test", but only need to look at two tables: The Paired Samples Statistics table and the Paired Samples Test table.

Table 4: Paired Samples Statistics

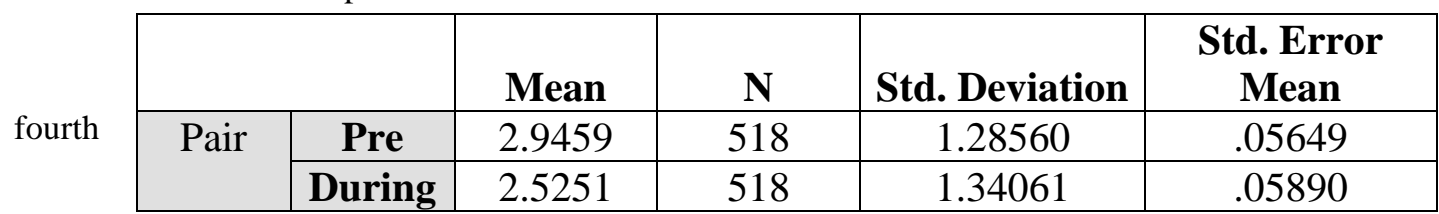


titled Paired Samples Statistics, is where SPSS Statistics has generated descriptive statistics for categorial variables.

Table 5: Paired Samples Correlations

\begin{tabular}{|l|c|c|c|c|}
\hline \multicolumn{2}{|c|}{} & N & Correlation & Sig. \\
\hline Pair & $\begin{array}{c}\text { Pre and } \\
\text { During }\end{array}$ & 518 & .207 & .000 \\
\hline
\end{tabular}

The Paired Samples Test table is where the results of the dependent t-test are presented. A lot of information is presented here and it is important to remember that this information refers to the differences between the Pre and During lockdown period (the subtitle reads "Paired Differences"). As such, the columns of the table labelled "Mean", "Std. Deviation", "Std. Error Mean" and "95\% Confidence Interval of the Difference" refer to the mean difference between the pre and during and the standard deviation, standard error and $95 \%$ confidence interval of this mean difference, respectively. The last three columns express the results of thedependent t-test, namely the t-value ("t"), the degrees of freedom ("df") and the significance level ("Sig. (2-tailed)") shown in table 6

Table 6: Paired Samples t-Test

\begin{tabular}{|c|c|c|c|c|c|c|c|c|c|}
\hline & \multicolumn{5}{|c|}{ Paired Differences } & \multirow[b]{3}{*}{$\mathbf{t}$} & \multirow[b]{3}{*}{ df } & \multirow{3}{*}{$\begin{array}{l}\text { Sig. (2- } \\
\text { tailed) }\end{array}$} \\
\hline & & \multirow[b]{2}{*}{ Mean } & \multirow{2}{*}{$\begin{array}{c}\text { Std. } \\
\text { Deviation }\end{array}$} & \multirow{2}{*}{$\begin{array}{l}\text { Std. } \\
\text { Error } \\
\text { Mean } \\
\end{array}$} & \multicolumn{2}{|c|}{$\begin{array}{c}\text { 95\% Confidence } \\
\text { Interval of the } \\
\text { Difference } \\
\end{array}$} & & & \\
\hline & & & & & Lower & Upper & & & \\
\hline Pair & $\begin{array}{l}\text { Pre and } \\
\text { During }\end{array}$ & .42085 & 1.65394 & .07267 & .27809 & .56361 & 5.791 & 517 & .000 \\
\hline
\end{tabular}

Reporting the Output of the paired t-Test

Reported the statistics in the following format: $\operatorname{tdf}(517)=5.791$, significant at $5 \%$ level of significance $(\mathrm{p}=$ significance level). In our case this would be: $\mathrm{t}(517)=5.791, \mathrm{p}<0.0005$. Due to the means of the pre and during covid-19 period and the direction of the t-value, we can conclude that there was a statistically significant change in the needs and hierarchy of consumers as suggested by the Maslow theory from $0.278 \pm 0.073$ to $0.564 \pm 0.073$ ( $\mathrm{p}<0.0005)$; an improvement of $0.286 \pm 0.286$.

\section{Conclusion}

The statistics found after the data analysis revealed that there is a significant difference between the pair of statistics, which suggests that respondent's behaviour was different between the two sets of time period that means pre and during the lockdown period.The results show that it was social needs before the lockdown period, but it is safety needs that are their utmost pre- requisite. The findings clearly evident that there may not consistent kind of needs and the similar behaviour of the consumers, but it may vary drastically when the surroundings environment is empiercing and changing its structure, Covid-19 pandemic generated scenario can be one of the reasons for gearing up changes in the consumer's requirements. Understanding thesechanges in behaviour that exhibited with the research process is important to gain insight for corporations and firms to analyse future trends of trade.

\section{References}

1. Aarts H, Hassin RR. (2005), Automatic goal inference and contagion: On pursuing goals one perceives in other people's behavior. In: Forgas JP, Williams KD, Laham SM, editors. Social motivation: Conscious and unconscious processes. New York: Cambridge University Press; pp. 153-167.

2. A.H. Maslow (1943) A Theory of Human Motivation, Originally Published in Psychological Review, 50, 370-396 (http://psychclassics.yorku.ca/Maslow/motivation.htm)

3. Andrew B Trigg (2007) Deriving the Engel Curve: Pierre Bourdieu and the Social Critique of Maslow's Hierarchy of Needs- Pages 393-406 | Published online: 18 Feb 2007 (https://doi.org/10.1080/0034676042000253987)

4. Ap. Dijksterhuis, Pamela K. Smith, Rick B. van Baaren\&Daniël H.J. Wigboldus (2008) The Unconscious Consumer: Effects of Environment on Consumer Behavior, (https://doi.org/10.1207/s15327663jcp1503_3)

5. Benjamin J. Ryan, Damon Coppola, Deon V. Canyon, Mark Brickhouse (2020) COVID-19 Community Stabilization and Sustainability Framework: An Integration of the Maslow Hierarchy of Needs and Social Determinants of Health DOI: https://doi.org/10.1017/dmp.2020.109, Cambridge University Press

6. Bibi Alajmi, HessahAlasousi (2019) Understanding and motivating academic library employees: theoretical implications, Library Management ISSN: 0143-5124 
7. Fallatah R.H.M., Syed J. (2018) A Critical Review of Maslow's Hierarchy of Needs. In: Employee Motivation in Saudi Arabia. Palgrave Macmillan, Cham. https://doi.org/10.1007/978-3-319-67741-5_2

8. Foxall, G.R. (Ed.) (2002) Consumer Behaviour Analysis: Critical Perspectives, London and NewYork. Routledge

9. Gross M. (1984) Sunfish, Salmon, and the evolution of alternative reproductive strategies and tactics in fishes. In: Potts G, Wootton R, editors. Fish reproduction: Strategies and tactics. New York: Academic Press; pp. $55-75$.

10. Harlow, H. F., Uehling, H. \& Maslow, A. H. (1932). Comparative behavior of primates: I. Delayed reaction tests on primates from the lemur to the orangoutan. Journal of Comparative Psychology, 13, 313-343.

11. Khan M. (2007) Consumerbehavior, New Age International

12. Kira Lussier (2019) Of Maslow, motives, and managers: The hierarchy of needs in American business, 1960 1985 Willey online Library, Journal of the history of the behavioralSciences (5)https://doi.org/10.1002/jhbs.21992

13. Leon G. Schiffman \& Leslie Lazar Kanuk, (1998) Consumer Behavior, Sixth Edition Prentice Hall of India Pvt. Ltd.

14. Priest, J., Carter, S., \& Stat, D. (2013). Consumer Behavior. Edinburgh Business School Press, United Kingdom.

15. Rodríguez-Ardura I., Martínez-López F.J., Gázquez-Abad J.C., Ammetller G. (2017) A Review of Online Consumer Behaviour Research: Main Themes and Insights. In: Campbell C.L. (eds) The Customer is NOT Always Right? Marketing Orientations in a Dynamic Business World. Developments in Marketing Science: Proceedings of the Academy of Marketing Science. Springer, Cham (DOIhttps://doi.org/10.1007/978-3-31950008-9_161)

16. Roelien Goede \& Christine Boshuizen-van Burken, (2019) A critical systems thinking approach to empower refugees based on Maslow's theory of human motivation,Willey online Library Systems Research and Behavioral Science.

17. Russell W. Belk, (1975) Situational Variables and Consumer Behavior, Journal of Consumer Research, Volume 2, Issue 3, December 1975, Pages 157-164,https://doi.org/10.1086/208627.

18. Smith, B.(1973) On self-actualization: A transambivalent examination of a focal theme in Maslow's psychology. Journal of Humanistic Psychology, SAGE Journals, 13(2), 17-33.

19. Suzanne G. Benson \& Stephen P. Dundis JD, (2003) Understanding and motivating health care employees: integrating Maslow's hierarchy of needs, training and technology, Wiley online Library, Journal for Nursing Management, Volume11, Issue5 Pages 315-320, https://doi.org/10.1046/j.1365-2834.2003.00409.x

20. Vance F.Mitchell Pravin Moudgill (1976) Measurement of Maslow's need hierarchy Elsevier Journal of Organizational Behavior and Human Performance, Volume 16, Issue 2, Pages 334-349

21. WHO statement regarding cluster of pneumonia cases in Wuhan, China.(https://www.who.int/china/news/detail/09-01-2020-who-statement-regarding-cluster-of-pneumoniacases-in-wuhan-china- Jan 9, 2020-Date accessed: February 11, 2020)

22. Wicker,Frank W.,Brown,Gail,Wiehe,James A.,Hagen,Anastasia S.,ReedJoy, Lynn (1993) Journal of Research in Personality -Elsevier Volume 27, Issue 2, June, Pages 118-133.Web Resource-

23. Singh R, Adhikari R (2020) Age-structured impact of social distancing on the COVID-19 epidemic in India. Quant Biol (Popul Eval) 1-9. https://arxiv.org/abs/2003.12055

24. World Health Organisation. Strategies, plans andperations. (https://www.who.int/emergencies/diseases/novel-coronavirus-2019/strategies-plans-and-operations) 